\section{Modelo preditivo de retenção no cuidado especializado em HIV/aids}

\section{A predictive model for retention in specialized HIV/AIDS care}

\section{Modelo predictivo de retención en el cuidado especializado en VIH/SIDA}

Wenislayne de Araújo Miranda 1 Leidyanny Barbosa de Medeiros 1 João Agnaldo do Nascimento 1 Kátia Suely Queiroz Silva Ribeiro 1 Jordana de Almeida Nogueira 1 Oriana Deyze Correia Paiva Leadebal 1

doi: 10.1590/0102-311X00209416

Correspondência

W. A. Miranda

Universidade Federal da Paraíba.

O estabelecimento de metas universais voltadas ao controle do HIV/aids e a instituição do tratamento como forma de prevenção reforçam a necessidade do acompanhamento clínico continuado das pessoas vivendo com HIV/aids como um elemento indispensável ao cuidado destas, sendo a retenção no cuidado em saúde uma necessidade e um desafio. Neste estudo, objetivou-se construir um modelo preditivo de retenção de pessoas vivendo com HIV/aids no cuidado em saúde. Para tanto foi construído um modelo estatístico, árvore de decisão, com base em variáveis sociodemográficas, clinicas e relacionadas aos comportamentos em saúde, identificadas em um banco de dados que contemplava informações de 260 pessoas com HIV/aids, vinculadas a um serviço especializado no atendimento a estes indivíduos. O modelo subsidiou a identificação de nove variáveis cujos ganhos de informação foram significativos em relação à variável desfecho, provável retenção no cuidado em saúde, e à construção de 24 regras de decisão, dando origem a uma árvore com porcentual de acerto de 80,4\%, as quais poderão contribuir com a identificação de possíveis estratégias no sentido de otimizar a retenção e contribuir com o alcance das metas propostas para o enfrentamento da epidemia nos próximos anos.

Síndrome de Imunodeficiência Adquirida; Terapia Antirretroviral de Alta Atividade; Assistência à Saúde; Árvores de Decisões
Campus I, Castelo Branco, João Pessoa, PB 58051-900, Brasil. wenislayne@hotmail.com

1 Universidade Federal da Paraíba, João Pessoa, Brasil. 


\section{Introdução}

Mesmo com os avanços técnico-científicos e políticos voltados para a prevenção, o diagnóstico e o tratamento do HIV/aids, estima-se que, no mundo, 35 milhões de indivíduos infectados não conhecem seu estado sorológico, e aproximadamente metade das pessoas diagnosticadas não está inserida em nenhum tipo de serviço de assistência e cuidados em saúde 1,2 .

Esse panorama impulsionou o Programa Conjunto das Nações Unidas sobre HIV/aids (UNAIDS), em 2014, a convocar todos os países para instituírem metas que visam a maximizar os benefícios individuais e coletivos do diagnóstico e tratamento do HIV/aids 3,4.

A meta, conhecida como 90-90-90, propõe a ampliação do diagnóstico e o tratamento, de modo que 90\% das PVHA (pessoas vivendo com HIV/aids) conheçam seu estado sorológico, destas, 90\% utilizem a TARV (terapia antirretroviral) e 90\% das pessoas em uso da terapia medicamentosa específica atinjam supressão viral. Para tanto, indicou-se a expansão do tratamento imediato após o diagnóstico, ou seja, a rápida e sustentada instituição da TARV com vistas à melhora imunitária, redução do risco de progressão para a doença, morte prematura e transmissão do HIV 2,3,4,5.

Com o fim de alcançar a meta e controlar a epidemia até 2030, definiram-se pilares para serem monitorados mundialmente, no sentido de identificar, em cada realidade, a eficácia das intervenções. Esses pilares representam a série de etapas vivenciadas por PVHA, desde o diagnóstico da infecção até a supressão viral, considerada objetivo final do tratamento e cuidado contínuo, o que é denominado de cascata de cuidado contínuo. No Brasil, a cascata é constituída de seis pilares, que contabilizam o número de pessoas inseridas na prestação de serviços específicos em todas as etapas do cuidado. São eles: PVHA, pessoas diagnosticadas, vinculadas ao cuidado, retidas no cuidado em saúde, em uso da TARV e com supressão viral. Essa última é obtida com a utilização da terapia medicamentosa específica 4,5,6.

Considera-se retida no cuidado a PVHA que está vinculada a um serviço de cuidado em HIV, com acesso contínuo a um atendimento adequado de acordo com as necessidades de atenção à saúde e permanência do seguimento no serviço ${ }^{6}$. Há evidências de que se trata de um comportamento que deve ser estimulado nas PVHA, para que se possa instituir oportunamente a TARV, reduzir a resistência medicamentosa e a carga viral, aumentar a contagem de linfócitos T CD4+, melhorar as condições clínicas e aumentar a taxa de sobrevivência 7.

Apesar de ser um elemento prioritário no cuidado de PVHA e um importante pilar da cascata de cuidado, a retenção é um desafio no Brasil e no mundo, que vem demandando, para fins de melhorias, a compreensão de barreiras e dos aspectos facilitadores, cujas origens intrínsecas ao próprio indivíduo, relacionados aos serviços de saúde e ao ambiente externo 7,8,9, devem ser enfrentadas.

A retenção de PVHA no cuidado em saúde é reconhecidamente essencial para que a epidemia seja controlada nas próximas duas décadas. Portanto, a necessária consideração dos aspectos locais de interferência sobre esse elemento da cascata de cuidados e a importância da instrumentalização dos profissionais para que suas ações estimulem a retenção instigaram a construção deste estudo, que objetivou construir um modelo preditivo de retenção de PVHA no cuidado em saúde, e pretende contribuir para que se possam identificar possíveis estratégias, no sentido de otimizar a retenção de PVHA no cuidado e de colaborar com o alcance das metas.

Para predizer a retenção no cuidado, o estudo considerou as condições inerentes à vinculação e à permanência de pessoas com HIV/aids no seguimento, tendo como referência o serviço ambulatorial especializado. A escolha foi pautada na relevância desse serviço na oferta de ações destinadas ao acompanhamento das condições de saúde de PVHA e na influência do serviço no modo como essas pessoas se relacionam com outros serviços da rede de atenção.

\section{Método}

Trata-se de um estudo por meio do qual se pretendeu elaborar uma árvore de decisão, um modelo estatístico em que se utiliza a técnica de mineração de dados para classificá-los, e é capaz de conduzir o pesquisador a predizer um desfecho de interesse com vistas a apoiar a decisão sobre este desfecho 10 .

Com esse modelo, podem-se identificar variáveis independentes, disponíveis em uma base de dados, que consistirão em variáveis decisórias que embasarão a construção de regras de classificação 
(representações textuais obtidas de sua estrutura), cuja disposição gráfica produz uma estrutura semelhante a uma árvore invertida 11.

A árvore é, portanto, composta de variáveis decisórias dispostas hierarquicamente, a partir do nó raiz (primeira variável), cujas regras de classificação conduzem aos nós internos e aos seus ramos, em direção ao nó terminal com a decisão. Esse é um recurso de baixo custo, que facilita a interpretação de dados por meio de visualização gráfica com potenciais para apoiar decisões relativas à saúde 10,11.

Para construir o modelo, utilizaram-se as variáveis do banco de dados da pesquisa Abandono do Acompanhamento Clínico Ambulatorial Especializado de Pessoas Vivendo com HIV/Aids 12, obtidas por fonte secundária (prontuários). A amostra foi composta por 260 casos de aids, selecionados de uma população de 1.941 adultos notificados no Sistema de Informação de Agravo de Notificação/aids (SINAN/ aids) no Estado da Paraíba, Brasil, de janeiro de 2007 a dezembro de 2013, maiores de 18 anos e vinculados ao ambulatório especializado de referência no estado para a realização do acompanhamento clínico.

A amostra foi definida por cálculo amostral para populações finitas, e selecionada utilizandose a técnica de amostragem aleatória simples. O critério de exclusão adotado englobou gestantes e pessoas privadas de liberdade. Para definir os casos de retenção foram considerados os registros no prontuário do comparecimento no serviço para fins de consulta e/ou exame, com intervalo de tempo máximo de sete meses. Para determinar esse período, ponderou-se que os indivíduos clinicamente estáveis poderiam retornar às consultas de acompanhamento clínico até o intervalo máximo de seis meses, com um prazo de um mês para os casos em que seria preciso remarcar a consulta, conforme rotina do serviço.

Para construir a árvore de decisão utilizou-se o programa Waikato Environment for Knowledge Analysis (Weka) versão 3.7.8 (https://www.cs.waikato.ac.nz/ml/weka/downloading.html), e para selecionar as variáveis do banco incluídas no modelo considerou-se o GI (ganho de informação) de cada variável em relação à variável desfecho (retenção no cuidado em saúde). O GI foi obtido com o cálculo de probabilidade das decisões no conjunto do banco de dados e nos subconjuntos de variáveis independentes relacionadas à decisão. Com base na distribuição numérica do GI de cada variável, foram selecionadas as com maior ganho de informação a respeito do desfecho. Essas variáveis foram distribuídas na árvore de forma hierárquica, considerando-se a ordem decrescente do GI.

Tendo em vista os critérios descritos, foram incluídas no modelo as seguintes variáveis sociodemográficas: idade (menos de 20 anos, 20-39, 40-59, 60 anos ou mais), estado civil (solteiro, casado/ união estável, separado/viúvo) e residência no mesmo município do serviço onde realiza o acompanhamento (sim, não). Dentre as variáveis de hábitos de vida e agravos associados: orientação sexual (homossexual, heterossexual, bissexual e informação ignorada no prontuário) e uso de bebida alcoólica (sim, não); e dentre as variáveis clínicas: uso da TARV (sim, não), resultado da última carga viral (indetectável, detectável, não realizou), internações no serviço (sim, não) e número de comprimidos (TARV) utilizados por dia (menos de quatro comprimidos/dia, mais de quatro comprimidos/dia).

As variáveis do banco de dados que não obtiveram GI significativo e, por isto, não foram incluídas no modelo, apesar de a literatura sugerir relação com a retenção no cuidado, foram: sexo, raça, escolaridade, uso de drogas ilícitas, tempo de diagnóstico e presença de doenças crônicas.

Para o desenvolvimento do trabalho, obedeceu-se aos preceitos éticos da pesquisa que envolve seres humanos, contidos na Resolução no 466/2012, incluindo a submissão do estudo e sua aprovação pelo Comitê de Ética da Universidade Federal da Paraíba (UFPB), sob o CAAE 41019115.7.0000.5188/2015.

\section{Resultados}

O estudo mostrou que houve um percentual de retenção correspondente a 68,5\%, e uma amostra caracterizada por prevalência do sexo masculino (64,6\%), solteiros (45\%), heterossexuais (69,3\%), com uma variação da faixa etária de 18-71 anos, média de 42,3 anos e predominância da faixa de 20-39 anos $(60,4 \%)$. Somente $37,7 \%$ residiam no município de localização do serviço de saúde responsável pelo acompanhamento; 92,3\% dos usuários usavam a TARV, 91,2\% apresentaram CV (carga viral) detectável no início do acompanhamento clínico ambulatorial; 65\% apresentaram CV indetectável no último registro; e 53,1\% tomavam mais de quatro comprimidos por dia. 
A árvore de decisão construída (Figura 1) apresentou porcentual de acerto de 80,4\% e capacidade de classificar corretamente 209 indivíduos conforme a matriz de decisão (Tabela 1), que apresenta os acertos localizados na diagonal principal e os erros identificados fora dela.

Para verificar a qualidade do modelo também foram empregadas medidas de validação (Tabela 2), cujos resultados demonstraram uma boa sensibilidade (aproximadamente 80\%), a fim de identificar os prováveis indivíduos não retidos no cuidado e razão de verossimilhança positiva, o que indica que a chance de identificar provável não retenção no cuidado é quatro vezes maior quando se aplica o modelo. Essas medidas fundamentaram a validade do modelo para predizer o desfecho investigado.

A árvore proporcionou o estabelecimento de 24 regras de decisão (Quadro 1) para a amostra estudada. Isso deixa clara a importância das variáveis utilizadas como decisórias para predizer a retenção de PVHA no cuidado em saúde.

As variáveis mais próximas da raiz da árvore ou do nó principal foram as que apresentaram maior GI. Isso significa que seus resultados conduzem a uma maior ou menor probabilidade de que ocorra o desfecho. Assim, "Uso da TARV” foi a variável com o maior ganho de informação, que constitui o nó principal da árvore, o qual se ramifica para os nós internos (formados pelas demais variáveis) e as folhas que contêm a variável de decisão - provável retenção ou não das pessoas no cuidado em saúde.

Para exemplificar a aplicabilidade do modelo, suas regras foram aplicadas a um caso clínico (Quadro 2).

\section{Discussão}

O perfil sociodemográfico do estudo corrobora o comportamento epidemiológico da infecção nos cenários nacional e internacional e indica que houve predominância do sexo masculino e de heterossexuais $5,8,13$.

Apesar de o sexo não ter sido considerado pelo modelo como variável significativa para predizer a retenção, a análise da proporção, por sexo, no cenário estudado (relação de 1,8:1, ou seja, 18 homens para cada dez mulheres) corrobora os resultados de um estudo desenvolvido em outro estado do Nordeste brasileiro, reafirmando o aumento do número de casos entre as mulheres, o que a literatura atribui, dentre outros fatores, ao aumento da transmissão heterossexual 14.

Em relação à faixa etária, estudos sugerem que há mais possibilidades de retenção com o aumento da idade, visto que, para cada ano a mais, o risco de uma não retenção no cuidado diminui de $4 \%$ a 5\%. Assim, os mais jovens (menos de 20 anos), conforme propõe o modelo, correm mais riscos de não retenção, o que se pode atribuir, segundo a literatura, ao fato de que os jovens têm mais dificuldade de adaptar seu estilo de vida à nova realidade requerida pelo tratamento, que envolve mudanças na alimentação, rotina de tomadas dos medicamentos e outros enfrentamentos psíquicos relacionados à convivência com a infecção 12,15,16,17.

Quanto ao estado civil, um trabalho desenvolvido em Santa Maria, Rio Grande do Sul, Brasil, sugere que o status solteiro pode contribuir com a vulnerabilidade para o abandono da TARV, considerando as associações entre esta condição civil e o isolamento social, a falta de suporte social e o abandono da terapia medicamentosa 18 . Levando-se em conta a intersecção entre adesão à TARV e retenção no cuidado, esse seria um resultado contraditório ao que propõe o modelo.

Entretanto, um estudo realizado no Rio de Janeiro, Brasil, que envolveu, especificamente, um universo masculino, sexo prevalente neste trabalho, menciona que, nos casos em que há ocultação da condição sorológica, um número maior de pessoas residentes no mesmo domicílio pode dificultar a tomada regular dos medicamentos 19. Tal achado poderia explicar a maior retenção por solteiros, separados e viúvos no modelo encontrado, considerando a probabilidade destes indivíduos conviverem com um menor número de pessoas no domicilio e a estreita relação entre adesão à TARV e a retenção no cuidado. No entanto, é necessário que outros trabalhos sejam realizados para compreender tal aspecto e quais fatores influenciam na maior retenção desses grupos independentemente da ocultação da condição sorológica ou não.

Sobre o local de residência, a prevalência dos que residem em outro município, para além da expressão do fenômeno de interiorização do HIV/aids no Estado da Paraíba, chama a atenção a influência negativa de barreiras geográficas sobre o acompanhamento da condição de saúde desses 


\section{Figura 1}

Árvore de decisão preditiva da retenção no cuidado em saúde de pessoas vivendo com HIV/aids. João Pessoa, Paraíba, Brasil, 2016.

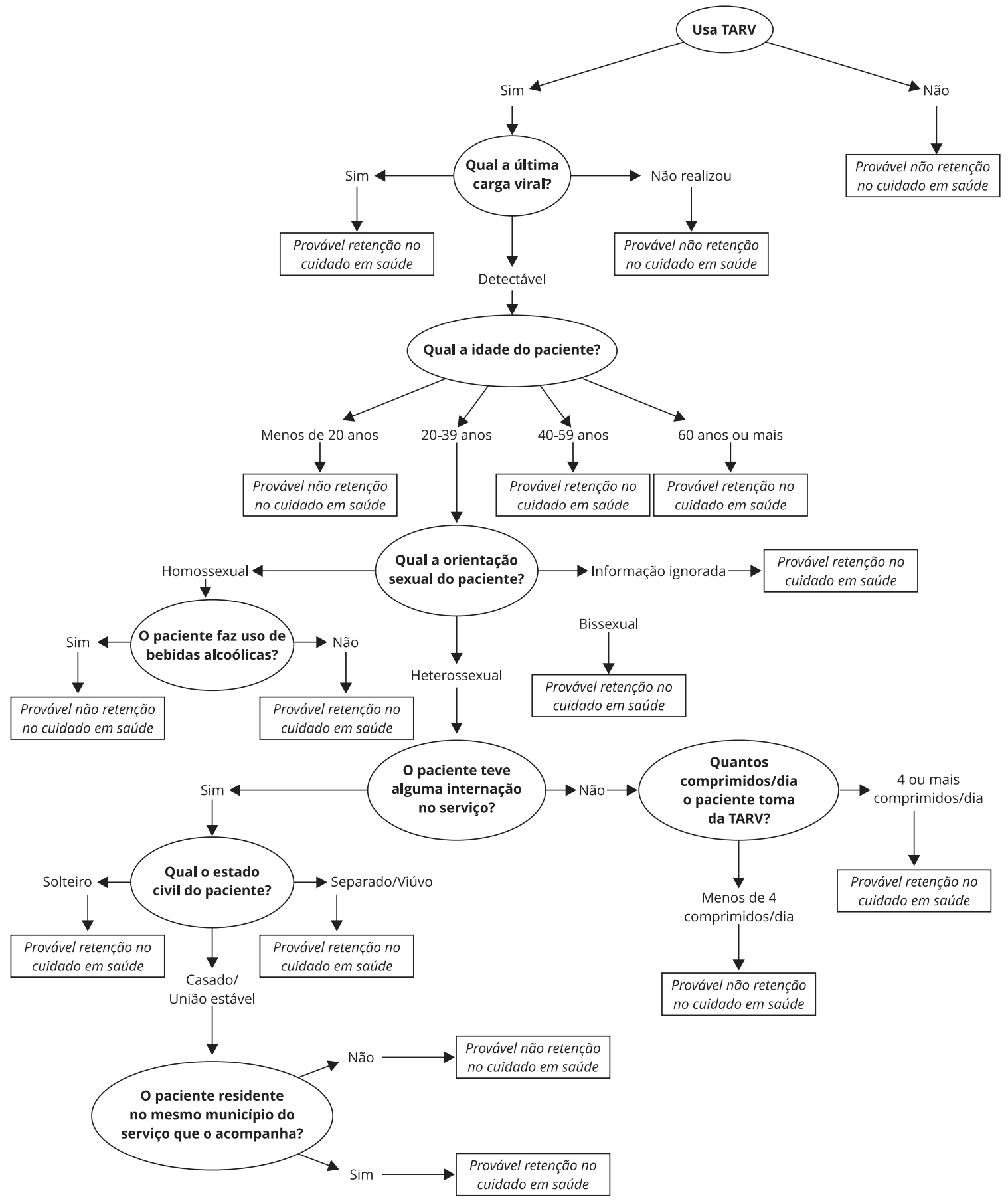

TARV: terapia antirretroviral.

Nota: O nó da árvore é a variável uso da terapia antirretroviral. 
Matriz de decisão para a retenção no cuidado em saúde de pessoas vivendo com HIV/aids. João Pessoa, Paraíba, Brasil, 2016

\begin{tabular}{|c|c|c|c|c|}
\hline \multicolumn{4}{|c|}{ Classificação da árvore de decisão } & \multirow[t]{2}{*}{ Total } \\
\hline & $\begin{array}{c}\text { Retenção no cuidado em } \\
\text { saúde }\end{array}$ & Provável não retenção & Provável retenção & \\
\hline \multirow{4}{*}{ Classificação da amostra (real) } & Não retenção & 43 * & 39 & 82 \\
\hline & Retenção & 12 & 166 * & 178 \\
\hline & Total & 55 & 205 & 260 \\
\hline & & Total de acertos & & $80,4 \%$ \\
\hline
\end{tabular}

* Diagonal principal contendo os acertos do modelo, totalizando $209(80,4 \%)$ indivíduos classificados corretamente.

Tabela 2

Medidas de validação do modelo de árvore de decisão.

\begin{tabular}{lcc}
\hline Qualidade do modelo & & IC95\% \\
\hline Acurácia & $80,4 \%$ & 75,$6 ; 85,2$ \\
Sensibilidade & $78,2 \%$ & 67,$3 ; 89,1$ \\
Especificidade & $81,0 \%$ & 75,$6 ; 86,3$ \\
Probabilidade pré-teste & $21,2 \%$ & 16,$2 ; 26,1$ \\
Valor preditivo positivo & $52,4 \%$ & 41,$6 ; 63,2$ \\
Valor preditivo negativo & $93,3 \%$ & 89,$6 ; 96,9$ \\
Razão de verossimilhança positiva & 4,1 & - \\
Razão de verossimilhança negativa & 0,3 & - \\
\hline
\end{tabular}

IC95\%: intervalo de 95\% de confiança.

usuários. Sabe-se que o aumento da infecção em pequenos municípios com menor renda per capita inclui os problemas de ordem financeira, de habitação e de transporte vivenciados por seus habitantes. Essas dificuldades aumentam ainda mais quando precisam se deslocar para o acesso à TARV, às consultas de acompanhamento e realização dos exames específicos 16,20,21 em outros municípios, o que pode comprometer a retenção no cuidado ambulatorial, conforme proposto pelo modelo.

Em relação às variáveis hábitos de vida e agravos associados, sabe-se que os indivíduos que usam, abusivamente ou não, bebidas alcoólicas apresentam maiores chances de não adesão à TARV e não retenção no cuidado 16,18 .

Quanto às variáveis clínicas, o modelo destacou o uso da TARV como a de maior GI em relação à retenção. De acordo com um estudo anterior 11, o risco de uma provável não retenção é reduzido em, aproximadamente, 61\%, quando os indivíduos usam a TARV. Isso reafirma a estreita relação entre esses dois pilares da cascata de cuidados 13. Considerando-se que, atualmente, o Ministério da Saúde recomenda a instituição da TARV imediatamente após o diagnóstico, independentemente da contagem de linfócitos T CD4+, sabendo-se da inter-relação entre adesão à TARV e retenção no cuidado 4,5 e das implicações da retenção e adesão inadequadas para os resultados individuais e populacional 13, a identificação, neste estudo, de um percentual de 92,3\% de adesão à TARV e de apenas $68,5 \%$ de retenção no cuidado suscita a necessidade de intervenções capazes de melhorar este último indicador.

O modelo verificou que os indivíduos com última carga viral indetectável tendem à retenção no cuidado. Em relação a essa variável, observou-se que houve um aumento do percentual de indivíduos 


\section{Quadro 1}

Regras de decisão elaboradas com base na árvore de decisão: a variável é a condição necessária (SE) e a decisão (ENTÃO) é o resultado obtido na variável de decisão. João Pessoa, Paraíba, Brasil, 2016.

\begin{tabular}{|c|c|}
\hline Atributo & Decisão \\
\hline 1. SE não houver uso da TARV & ENTÃO ocorrerá uma provável não retenção no cuidado em saúde \\
\hline 2. SE houver uso da TARV & ENTÃO será preciso averiguar qual foi a última carga viral \\
\hline 3. SE houver uso da TARV e a última carga viral for indetectável & ENTÃO ocorrerá uma provável retenção no cuidado em saúde \\
\hline 4. SE houver uso da TARV e não tiver sido realizado exame de carga viral & ENTÃO ocorrerá uma provável não retenção no cuidado em saúde \\
\hline 5. SE houver uso da TARV e a última carga viral for detectável & ENTÃO será preciso averiguar qual a idade do paciente \\
\hline $\begin{array}{l}\text { 6. SE houver uso da TARV e a última carga viral for detectável e o paciente } \\
\text { tiver menos de } 20 \text { anos }\end{array}$ & ENTÃO ocorrerá uma provável não retenção no cuidado em saúde \\
\hline $\begin{array}{l}\text { 7. SE houver uso da TARV e a última carga viral for detectável e o paciente } \\
\text { tiver de } 40-59 \text { anos }\end{array}$ & ENTÃO ocorrerá uma provável retenção no cuidado em saúde \\
\hline $\begin{array}{l}\text { 8. SE houver uso da TARV e a última carga viral for detectável e o paciente } \\
\text { tiver } 60 \text { anos ou mais }\end{array}$ & ENTÃO ocorrerá uma provável retenção no cuidado em saúde \\
\hline $\begin{array}{l}\text { 9. SE houver uso da TARV e a última carga viral for detectável e o paciente } \\
\text { tiver de } 20-39 \text { anos }\end{array}$ & ENTÃO será preciso averiguar qual a orientação sexual do paciente \\
\hline $\begin{array}{l}\text { 10. SE houver uso da TARV e houver carga viral detectável, o paciente tiver } \\
\text { de } 20-39 \text { anos e for homossexual }\end{array}$ & $\begin{array}{l}\text { ENTÃO será preciso averiguar se o paciente faz uso de bebidas } \\
\text { alcoólicas }\end{array}$ \\
\hline $\begin{array}{l}\text { 11. SE houver uso da TARV e a última carga viral for detectável, o paciente } \\
\text { tiver de 20-39 anos, for homossexual e fizer uso de bebidas alcoólicas }\end{array}$ & ENTÃO ocorrerá uma provável não retenção no cuidado em saúde \\
\hline $\begin{array}{l}\text { 12. SE houver uso da TARV e a última carga viral for detectável, o paciente } \\
\text { tiver de 20-39 anos, for homossexual e não fizer uso de bebidas alcoólicas }\end{array}$ & ENTÃO ocorrerá uma provável retenção no cuidado em saúde \\
\hline $\begin{array}{l}\text { 13. SE houver uso da TARV e a última carga viral for detectável, o paciente } \\
\text { tiver de 20-39 anos e for bissexual }\end{array}$ & ENTÃO ocorrerá uma provável retenção no cuidado em saúde \\
\hline $\begin{array}{l}\text { 14. SE houver uso da TARV e a última carga viral for detectável, o paciente } \\
\text { tiver de } 20-39 \text { anos e não tiver informação quanto à sua orientação sexual }\end{array}$ & ENTÃO ocorrerá uma provável retenção no cuidado em saúde \\
\hline $\begin{array}{l}\text { 15. SE houver uso da TARV e a última carga viral for detectável, o paciente } \\
\text { tiver de } 20-39 \text { anos e for heterossexual }\end{array}$ & $\begin{array}{l}\text { ENTÃO será preciso averiguar se o paciente teve alguma internação } \\
\text { no serviço }\end{array}$ \\
\hline $\begin{array}{l}\text { 16. SE houver uso da TARV e a última carga viral for detectável, o paciente } \\
\text { tiver de 20-39 anos, for heterossexual e já teve alguma internação no serviço }\end{array}$ & ENTÃO será preciso averiguar qual o estado civil do paciente \\
\hline $\begin{array}{l}\text { 17. SE houver uso da TARV e a última carga viral for detectável, o paciente } \\
\text { tiver de } 20-39 \text { anos, for heterossexual, já teve alguma internação no serviço e } \\
\text { o seu estado civil for solteiro }\end{array}$ & ENTÃO ocorrerá uma provável retenção no cuidado em saúde \\
\hline $\begin{array}{l}\text { 18. SE houver uso da TARV e a última carga viral for detectável, o paciente } \\
\text { tiver de } 20-39 \text { anos, for heterossexual, já teve alguma internação no serviço e } \\
\text { o seu estado civil separado/viúvo }\end{array}$ & ENTÃO ocorrerá uma provável retenção no cuidado em saúde \\
\hline $\begin{array}{l}\text { 19. SE houver uso da TARV e a última carga viral for detectável, o paciente } \\
\text { tiver de } 20-39 \text { anos, for heterossexual, já teve alguma internação no serviço e } \\
\text { o seu estado civil for casado/união estável }\end{array}$ & $\begin{array}{l}\text { ENTÃO será preciso averiguar se o paciente reside no mesmo } \\
\text { município do serviço que o acompanha }\end{array}$ \\
\hline $\begin{array}{l}\text { 20. SE houver uso da TARV e a última carga viral for detectável, o paciente } \\
\text { tiver de 20-39 anos, for heterossexual, já teve alguma internação no serviço e } \\
\text { o seu estado civil for casado/união estável e residir no mesmo município do } \\
\text { serviço que o acompanha }\end{array}$ & ENTÃO ocorrerá uma provável retenção no cuidado em saúde \\
\hline $\begin{array}{l}\text { 21. SE houver uso da TARV e a última carga viral for detectável, o paciente } \\
\text { tiver de } 20-39 \text { anos, for heterossexual, já teve alguma internação no serviço e } \\
\text { o seu estado civil for casado/união estável e não residir no mesmo município } \\
\text { do serviço que o acompanha }\end{array}$ & ENTÃO ocorrerá uma provável não retenção no cuidado em saúde \\
\hline $\begin{array}{l}\text { 22. SE houver uso da TARV e houver carga viral detectável, o paciente tiver } \\
\text { de 20-39 anos, for heterossexual e não teve nenhuma internação no serviço }\end{array}$ & $\begin{array}{l}\text { ENTÃO será preciso averiguar quantos comprimidos/dia o paciente } \\
\text { toma da TARV }\end{array}$ \\
\hline $\begin{array}{l}\text { 23. SE houver uso da TARV e houver carga viral detectável, o paciente tiver } \\
\text { de } 20-39 \text { anos, for heterossexual, não teve nenhuma internação no serviço e } \\
\text { faz uso de menos de } 4 \text { comprimidos/dia da TARV }\end{array}$ & ENTÃO ocorrerá uma provável não retenção no cuidado em saúde \\
\hline $\begin{array}{l}\text { 24. SE houver uso da TARV e houver carga viral detectável, o paciente tiver } \\
\text { de } 20-39 \text { anos, for heterossexual, não teve nenhuma internação no serviço e } \\
\text { faz uso de } 4 \text { ou mais comprimidos/dia da TARV }\end{array}$ & ENTÃO ocorrerá uma provável retenção no cuidado em saúde \\
\hline
\end{tabular}

TARV: terapia antirretroviral.

Fonte: elaboração própria. 


\section{Quadro 2}

Aplicação das regras extraídas da árvore de decisão.

\begin{tabular}{|c|c|}
\hline Caso clínico & Aplicação do modelo \\
\hline $\begin{array}{l}\text { Usuário do sexo masculino, } 19 \text { anos, homossexual. No momento } \\
\text { da notificação, apresentou algumas manifestações clínicas, faz uso } \\
\text { da terapia antirretroviral, com ingesta de } 2 \text { comprimidos ao dia, e a } \\
\text { sua última carga viral, há } 3 \text { meses, foi detectável. Sem internações } \\
\text { anteriores no serviço. } \\
\text { Diante desse contexto, qual será o comportamento desse paciente } \\
\text { frente ao acompanhamento/retenção no serviço/rede de atenção? }\end{array}$ & $\begin{array}{l}\text { As variáveis decisórias da árvore são dispostas hierarquicamente, a } \\
\text { partir do nó raiz (primeira variável). Neste modelo está representado } \\
\text { pela variável uso da TARV. Iniciando a interpretação pela regra 2: SE } \\
\text { houver uso da TARV, ENTÃO será preciso averiguar qual foi a última } \\
\text { carga viral. Como nesse caso a última carga viral foi detectável, deve- } \\
\text { se analisar a eegra 5: SE houver uso da TARV e a última carga viral for } \\
\text { detectável, ENTÃO será preciso averiguar qual a idade do paciente. } \\
\text { Como o paciente tem } 19 \text { anos, a regra } 6 \text { será utilizada: SE houver uso } \\
\text { da TARV e a última carga viral for detectável e o paciente tiver menos } \\
\text { de } 20 \text { anos, ENTÃO ocorrerá uma provável não retenção no cuidado } \\
\text { em saúde. }\end{array}$ \\
\hline
\end{tabular}

TARV: terapia antirretroviral.

Fonte: elaboração própria.

com carga viral indetectável, quando se comparou com o início do tratamento (8,8\%) e o último registro deste indicador (65\%), o que pode ser atribuído à utilização adequada da TARV. Apesar de positivo, esse percentual ainda é insuficiente para que seja possível alcançar as metas.

No que se refere ao número de comprimidos utilizados, o estudo demonstrou que o uso de quatro ou mais contribuiria para a retenção. Reportando-se à inter-relação entre adesão à TARV e retenção no cuidado, conforme já mencionado, esse achado contraria alguns trabalhos que sugerem que quanto maior o número de medicamentos do esquema terapêutico menor a adesão e, portanto, a retenção 8,19,22.

Nesse aspecto, há que se destacar a necessidade de acompanhamento mais frequente das interações medicamentosas e dos efeitos colaterais quando há mais comprimidos no esquema, um possível fator que contribui para aproximar bem mais os usuários nestas condições do serviço responsável pelo manejo clínico 15 e com a retenção, caso o serviço seja atuante nesta perspectiva. Por essa razão, a equipe deve valorizar os cuidados, na expectativa de simplificar os esquemas e de dar suporte às adaptações da rotina, o que requer o estreitamento de vínculo entre o serviço de saúde e as PVHA para fortalecer a retenção $23,24,25$.

Observou-se um percentual de retenção 68,5\% superior ao nacional, que é de 66\% (dentre $83 \%$ dos indivíduos diagnosticados soropositivos), segundo o último boletim epidemiológico de HIV/aids 4,13. Diante desse cenário, compreende-se a relevância do planejamento de ações e de estratégias locais capazes de melhorar todos os pilares da cascata de cuidados, principalmente os relacionados à adesão à TARV e à retenção no cuidado para o alcance das metas 26,27. Nesse contexto, a identificação precoce de fatores desencadeantes de uma retenção e não retenção é fundamental para que os profissionais do serviço especializado possam atuar maximizando os aspectos facilitadores da retenção e reduzir a capacidade dos aspectos impeditivos 28 .

Vale salientar a importância de estender a atenção dos profissionais para a família, considerando seu papel nesse contexto como um motivador para que as PVHA prossigam com o tratamento, a fim de melhorar sua qualidade de vida 29. 


\section{Considerações finais}

A retenção no cuidado em saúde de PVHA vem ganhando destaque graças à cascata de cuidados contínuos, razão por que é importante conhecer os fatores que contribuem para promover este fenômeno, com vistas a alcançar as metas de controle da epidemia.

Apesar das dificuldades do estudo, no que se refere à abordagem do tema "retenção" na literatura nacional para fins de discussão dos resultados considerando a realidade brasileira, da estreita relação entre este e outros fenômenos inerentes ao tratamento/cuidados da PVHA (como vinculação e adesão ao tratamento/cuidados), os resultados obtidos evidenciaram que a retenção no cuidado é influenciada por fatores sociodemográficos, de hábitos de vida e por variáveis clínicas, que merecem ser observados para que seja feita uma intervenção eficaz do serviço, na perspectiva de promover a retenção.

A árvore de decisão construída é, nesse sentido, um modelo que pode subsidiar os profissionais do serviço especializado para identificar aspectos por meio dos quais se interfira no processo de vinculação e da permanência (seguimento) de PVHA no serviço, instrumentalizando a identificação e o planejamento de intervenções preventivas da não retenção. O modelo pode ser utilizado, por exemplo, nas consultas de enfermagem, no sentido de qualificar o cuidado prestado por estes profissionais que constituem um importante contingente no cuidado especializado em discussão.

Como limitação do estudo, para fins de generalização, destaca-se o fato de a amostra ser proveniente de um único serviço, apesar de ser referência para o cuidado especializado no estado. Outras limitações incluem a fonte secundária de dados, cuja riqueza de resultados depende da qualidade dos registros, e a não consideração dos aspectos inerentes à organização do serviço no modelo.

Assim, considerando-se a importância da temática nos próximos anos, principalmente para o alcance das metas inerentes ao controle da epidemia, é necessário que outros trabalhos que contemplem variáveis individuais, sociais e programáticas sejam realizados, a fim de conhecer, com amplitude, os fatores que permeiam a retenção de PVHA no cuidado.

\section{Colaboradores}

W. A. Miranda trabalhou na concepção, delineamento do estudo, interpretação dos dados, redação e discussão do artigo. L. B. Medeiros trabalhou com delineamento do estudo, análise e interpretação dos dados, revisão final e aprovação da versão a ser publicada. O. D. C. P. Leadebal trabalhou na concepção, delineamento do estudo, metodologia e redação final. J. A. Nascimento e K. S. Q. S. Ribeiro contribuíram redação final e aprovação da versão a ser publicada. J. A. Nogueira trabalhou na revisão crítica, redação final e aprovação da versão a ser publicada.

\section{Referências}

1. Fonjungo PN, Osmanov S, Kuritsky J, Ndihokubwayo JB, Bachanas P, Peeling RW, et al. Ensuring quality: a key consideration in scaling-up HIV-related point-of-care testing programs. AIDS 2016; 30:1317-23.

2. Bemelmans M, Baert S, Negussie E, Bygrave $\mathrm{H}$, Biot M, Jamet C, et al. Sustaining the future of HIV counselling to reach 90-90-90: a regional country analysis. J Int AIDS Soc 2016; 19:20751.

3. Joint United Nations Programme on HIV/ AIDS. 90-90-90 An ambitious treatment target to help end the AIDS epidemic. Geneva: Joint United Nations Programme on HIV/AIDS; 2014. 
4. Nosyk B, Montaner JS, Colley G, Lima VD, Chan K, Heath K, et al. The cascade of HIV care in British Columbia, Canada, 1996-2011: a population-based retrospective cohort study. Lancet Infect Dis 2014; 14:40-9.

5. Departamento de DST, Aids e Hepatites Virais, Secretaria de Vigilância em Saúde, Ministério da Saúde. Boletim Epidemiológico Aids e DST 2015; VI(3).

6. Departamento de Vigilância, Prevenção e Controle das Infecções Sexualmente Transmissíveis, do HIV/Aids e das Hepatites Virais, Secretaria de Vigilância em Saúde, Ministério da Saúde. Manual técnico de elaboração da cascata de cuidado contínuo do HIV. Brasília: Ministério da Saúde; 2017.

7. Lourenço L, Nohpal A, Shopin D, Colley G, Nosyk B, Montaner JSG, et al. Non-HIV-related healthcare utilization, demographic, clinical and laboratory factors associated with timeto-initial retention in HIV care among HIVpositive individuals linked to HIV care. HIV Med 2016; 17:269-79.

8. Fiuza MLT, Lopes EM, Alexandre HO, Dantas PB, Galvão MTG, Pinheiro AKB. Adherence to antiretroviral treatment: comprehensive care based on the care model for chronic conditions. Esc Anna Nery Rev Enferm 2013; 17:740-8.

9. Holtzman CW, Brady KA, Yehia BR. Retention in care and medication adherence: current challenges to antiretroviral therapy success. Drugs 2015; 75:445-54.

10. Medeiros ARC, Araujo YB, Vianna RPT, Ronei MM. Modelo de suporte à decisão aplicado à identificação de indivíduos não aderentes ao tratamento anti-hipertensivo. Saúde Debate 2014; 38:104-18.

11. Medeiros LB, Trigueiro DRSG, Silva DM, Nascimento JA, Monroe AA, Nogueira JA, et al. Integração entre serviços de saúde no cuidado às pessoas vivendo com aids: uma abordagem utilizando árvore de decisão. Ciênc Saúde Coletiva 2016; 21:543-552.

12. Medeiros LB. Fatores influentes no abandono do acompanhamento clínico ambulatorial por pessoas vivendo com HIV/Aids, João Pessoa - PB [Dissertação de Mestrado]. João Pessoa: Universidade Federal da Paraíba; 2016.

13. Stricker SM, Fox KA, Baggaley R, Negussie E, de Pee S, Grede N, et al. Retention in care and adherence to ART are critical elements of HIV care interventions. AIDS Behav 2016; 18 Suppl 5:S465-75

14. Silva RAR, Silva RTS, Nascimento EGC, Gonçalves OP, Reis MM, Silva BCO. Perfil clínicoepidemiológico de adultos hiv-positivo atendidos em um hospital de Natal/RN. Rev Pesqui Cuid Fundam (Online) 2016; 8:4689-96.

15. Schilkowsky LB, Portela MC, Sá MC. Factors associated with HIV/AIDS treatment dropouts in a special care unit in the city of Rio de Janeiro, RJ, Brazil. Rev Bras Epidemiol 2011; $14: 187-97$.
16. Yehia BR, Fleishman JA, Metlay JP, Korthuis PT, Agwu AL, Berry SA, et al. Comparing different measures of retention in outpatient HIV care. AIDS 2012; 26:1131-9.

17. Naguchi NEO. Adesão ao tratamento dos portadores de HIV/AIDS: compartilhando desafios [Monografia de Especialização]. Florianópolis: Universidade Federal de Santa Catarina; 2016.

18. Padoin SMM, Zuge SS, Santos EEP, Primeira MR, Aldrighi JD, Paula CC. Adesão à terapia antirretroviral para HIV/Aids. Cogitare Enferm 2013; 18:446-51.

19. Moraes DCA, Oliveira RC, Costa SFG. Adherence of men living with HIV/AIDS to antiretroviral treatment. Esc Anna Nery Rev Enferm 2014; 18:676-81.

20. Silva JVF, Nascimento JFJM, Rodrigues APRA. Fatores de não adesão ao tratamento antirretroviral: desafio de saúde pública. Cadernos de Graduação: Ciências Biológicas e da Saúde 2014; 2:165-75.

21. Souza CC, Mata LRF, Azevedo C, Gomes CRG, Cruz GECP, Toffano SEM. Interiorização do HIV/Aids no Brasil: um estudo epidemiológico. Rev Bras Ciênc Saúde 2013; 11:25-30.

22. Oliveira EF, Paes MSL. Adesão ao tratamento antirretroviral de pessoas com HIV/Aids. Revista Enfermagem Integrada 2013; 6:1154-66.

23. Programa Nacional de DST e Aids, Secretaria de Vigilância em Saúde, Ministério da Saúde. Diretrizes para o fortalecimento das ações de adesão ao tratamento para pessoas que vivem com HIV e Aids. Brasília: Ministério da Saúde; 2007.

24. Tietzmann DC, Béria JU, Santos GM, Mallmann DA, Trombini ES, Schermann LB. Prevalências de adesão à terapia antirretroviral e fatores associados em pacientes adultos de três centros urbanos do Sul do Brasil. Aletheia 2013; 41:154-63

25. Moraes DCA, Oliveira RC, Motta MCS, Ferreira OLC, Andrade MS. Terapia antirretroviral: a associação entre o conhecimento e a adesão. Rev Pesqui Cuid Fundam (Online) 2015; 7:3563-73

26. Montaner JS. Treatment as prevention: toward an AIDS-free generation. Top Antivir Med 2013; 21:110-14

27. Silva JAG, Dourado I, Brito AM, Silva CAL. Fatores associados à não adesão aos antirretrovirais em adultos com AIDS nos seis primeiros meses da terapia em Salvador, Bahia, Brasil. Cad Saúde Pública 2015; 31:1188-98.

28. Figueiredo LA, Lopes LM, Magnabosco GT, Andrade RLP, Farias MF, Goulart VC, et al. Provision of health care actions and services for the management of HIV/AIDS from the users' perspective. Rev Esc Enferm USP 2014; 48:1026-34

29. Pereira PE, Espírito SCC, Tosoli GAM, Santos EI, Oliveira, Pontes APM. Adherence to antiretroviral therapy and its representations for people living with HIV/AIDS. Esc Anna Nery Rev Enferm 2014; 18:32-40. 


\section{Abstract}

The establishment of universal targets for HIV/ AIDS control and the implementation of treatment as prevention reinforce the need for on-going clinical follow-up of persons living with HIV/AIDS as an essential element of their care, where retention in care is both a need and a challenge. This study aimed to create a predictive model for retention of persons living with HIV/AIDS in health care. A decision tree statistical model was created, based on sociodemographic, clinical, and health behavior variables, identified in a database with information from 260 persons with HIV/AIDS, enrolled in a specialized treatment service. The model enabled the identification of nine variables with significant information gains in relation to the outcome variable, probable retention in health care, and the development of 24 decision rules, giving rise to a decision tree with $80.4 \%$ correct answers, which can help identify possible strategies to optimize retention and contribute to achieving the proposed targets for confronting the epidemic in the coming years.

Acquired Immunodeficiency Syndrome; Highly Active Antiretroviral Therapy; Delivery of Health Care; Decision Threes

\section{Resumen}

El estabelecimiento de metas universales dirigidas al control del VIH/SIDA, y la institución del tratamiento como forma de prevención, refuerzan la necesidad del seguimiento clínico continuado de las personas que viven con VIH/SIDA, como un elemento indispensable para el cuidado de estas, siendo la retención en el cuidado de salud una necesidad y un desafío. En este estudio, el objetivo fue construir un modelo predictivo de retención de personas viviendo con VIH/SIDA dentro del ámbito del cuidado en salud. Para tal fin, se construyó un modelo estadístico, un diagrama de árbol de decisión, en base a variables sociodemográficas, clínicas, y aquellas relacionadas con los comportamientos en salud, identificadas en un banco de datos que contemplaba información de 260 personas con VIH/SIDA, vinculadas a un servicio especializado en la atención a estos individuos. El modelo subsidió la identificación de nueve variables, cuyos réditos respecto a información fueron significativos en relación con la variable desenlace, probable retención en el cuidado en salud, y a la construcción de 24 reglas de decisión, dando origen a un árbol con un porcentaje de acierto de un 80,4\%, que podría contribuir a la identificación de posibles estrategias, en el sentido de optimizar la retención y contribuir al alcance de las metas propuestas para enfrentar la epidemia en los próximos años.

Sindrome de Inmunodeficiencia Adquirida; Terapia Antirretroviral Altamente Activa; Prestación de Atención de Salud; Árboles de Decisión
Recebido em 03/Dez/2016

Versão final reapresentada em 20/Fev/2018

Aprovado em 06/Mar/2018 